\title{
The UV absorption spectrum of the simplest Criegee intermediate $\mathrm{CH}_{2} \mathrm{OO} \dagger$
}

Cite this: Phys. Chem. Chem. Phys. 2014, 16, 10438

Received 28th February 2014, Accepted 14th April 2014

DOI: $10.1039 / c 4 c p 00877 d$

www.rsc.org/pccp

\author{
Wei-Lun Ting, ${ }^{a}$ Ying-Hsuan Chen, ${ }^{a}$ Wen Chao, ${ }^{\text {ab }}$ Mica C. Smith ${ }^{\text {ac }}$ and \\ Jim Jr-Min Lin*abd
}

$\mathrm{SO}_{2}$ scavenging and self-reaction of $\mathrm{CH}_{2} \mathrm{OO}$ were utilized for the decay of $\mathrm{CH}_{2} \mathrm{OO}$ to extract the absorption spectrum of $\mathrm{CH}_{2} \mathrm{OO}$ under bulk conditions. Absolute absorption cross sections of $\mathrm{CH}_{2} \mathrm{OO}$ at 308.4 and $351.8 \mathrm{~nm}$ were obtained from laser-depletion measurements in a jet-cooled molecular beam. The peak cross section is $(1.23 \pm 0.18) \times 10^{-17} \mathrm{~cm}^{2}$ at $340 \mathrm{~nm}$.

Ozonolysis is a major removal mechanism in the troposphere for unsaturated hydrocarbons which are emitted in large quantities from both natural and human sources. Now it is generally accepted that ozonolysis of alkenes proceeds via Criegee intermediates, highly reactive species postulated in 1949 by Rudolf Criegee. $^{1,2}$ In the troposphere, Criegee intermediates are involved in several important atmospheric reactions, ${ }^{3}$ including reactions with $\mathrm{SO}_{2}$ and $\mathrm{NO}_{2},{ }^{4-7}$ or can be photolyzed by near UV light, ${ }^{7-10}$ as shown for $\mathrm{CH}_{2} \mathrm{OO}$ in (R1)-(R4).

$$
\begin{aligned}
& \mathrm{C}_{2} \mathrm{H}_{4}+\mathrm{O}_{3} \rightarrow \mathrm{CH}_{2} \mathrm{OO}+\mathrm{H}_{2} \mathrm{CO} \\
& \mathrm{CH}_{2} \mathrm{OO}+\mathrm{SO}_{2} \rightarrow \mathrm{SO}_{3}+\mathrm{H}_{2} \mathrm{CO} \\
& \mathrm{CH}_{2} \mathrm{OO}+\mathrm{NO}_{2} \rightarrow \mathrm{NO}_{3}+\mathrm{H}_{2} \mathrm{CO} \\
& \mathrm{CH}_{2} \mathrm{OO}+h \nu \rightarrow \mathrm{O}\left({ }^{1} \mathrm{D}\right)+\mathrm{H}_{2} \mathrm{CO}
\end{aligned}
$$

The formation of $\mathrm{SO}_{3}$ and $\mathrm{NO}_{3}$, as in (R2) and (R3), plays an important role in atmospheric chemistry, ${ }^{11,12}$ including aerosol and cloud formation. The formation of $\mathrm{O}\left({ }^{1} \mathrm{D}\right)$, as in (R4), will result in $\mathrm{OH}$ formation through (R5).

$$
\mathrm{O}\left({ }^{1} \mathrm{D}\right)+\mathrm{H}_{2} \mathrm{O} \rightarrow 2 \mathrm{OH}
$$

\footnotetext{
${ }^{a}$ Institute of Atomic and Molecular Sciences, Academia Sinica, Taipei 10617, Taiwan

${ }^{b}$ Department of Chemistry, National Taiwan University, Taipei 10617, Taiwan

${ }^{c}$ Department of Chemistry, University of California at Berkeley, Berkeley, CA 94720, USA

${ }^{d}$ Department of Applied Chemistry, National Chiao Tung University, Hsinchu 30010, Taiwan.E-mail: jimlin@gate.sinica.edu.tw

$\dagger$ Electronic supplementary information (ESI) available. See DOI: 10.1039/ c4cp00877d
}

Because $\mathrm{CH}_{2} \mathrm{OO}$ absorbs strongly at wavelengths longer than $300 \mathrm{~nm},{ }^{7-9}$ tropospheric photolysis of $\mathrm{CH}_{2} \mathrm{OO}$ would be quite efficient with an effective photolysis lifetime on the order of 1 second. $^{8}$ As a result, the $\mathrm{OH}$ formation of (R4) + (R5) may contribute significantly to the atmospheric $\mathrm{OH}$ concentrations.

Despite their importance, the direct detection of Criegee intermediates was not realized until recently. ${ }^{4,13}$ Welz et al. ${ }^{4}$ reported an efficient way to prepare Criegee intermediates. For example, $\mathrm{CH}_{2} \mathrm{OO}$ can be prepared via (R6) + (R7a).

$$
\begin{gathered}
\mathrm{CH}_{2} \mathrm{I}_{2}+h \nu \rightarrow \mathrm{CH}_{2} \mathrm{I}+\mathrm{I} \\
\mathrm{CH}_{2} \mathrm{I}+\mathrm{O}_{2} \rightarrow \mathrm{CH}_{2} \mathrm{OO}+\mathrm{I}
\end{gathered}
$$

Welz et al. ${ }^{4}$ also demonstrated the direct detection of $\mathrm{CH}_{2} \mathrm{OO}$ by using vacuum UV photoionization mass spectrometry. The parent ion $\mathrm{CH}_{2} \mathrm{O}_{2}{ }^{+}$was observed when the photon energy exceeded the ionization energy of $\mathrm{CH}_{2} \mathrm{OO}(10.0 \mathrm{eV})$; other isomers like dioxirane and formic acid were excluded due to their different ionization energies. ${ }^{4}$ At low pressure, the yield of (R7a) is close to unity, ${ }^{14,15}$ while the adduct formation (R7b) may dominate at near atmospheric pressures. ${ }^{14}$

$$
\mathrm{CH}_{2} \mathrm{I}+\mathrm{O}_{2}+\mathrm{M} \rightarrow \mathrm{ICH}_{2} \mathrm{OO}+\mathrm{M}
$$

The kinetics of $\mathrm{CH}_{2} \mathrm{OO}$ reactions with $\mathrm{SO}_{2}$ and $\mathrm{NO}_{2}$ were investigated by Welz et al. ${ }^{4}$ and by Stone et al. ${ }^{5}$ by observing the disappearance of $\mathrm{CH}_{2} \mathrm{OO}$ and by detecting the $\mathrm{H}_{2} \mathrm{CO}$ products, respectively. The rate coefficients of these reactions were found to be unexpectedly rapid and imply a substantially greater role of Criegee intermediates in models of tropospheric sulfate and nitrate chemistry.

Beames et al. ${ }^{8}$ recorded the UV spectrum of $\mathrm{CH}_{2} \mathrm{OO}$ through observing its depletion in a molecular beam upon laser irradiation (an action spectrum). Based on their laser pulse energy and spot size, Beames et al. ${ }^{8}$ roughly estimated the peak absorption cross section to be $5 \times 10^{-17} \mathrm{~cm}^{2}$ (at $335 \mathrm{~nm}$ with FWHM $\sim 40 \mathrm{~nm})$. Lehman et al. ${ }^{10}$ measured the angular and velocity distributions of the $\mathrm{O}\left({ }^{1} \mathrm{D}\right)$ photoproduct arising from UV excitation of $\mathrm{CH}_{2} \mathrm{OO}$ in the $300-365 \mathrm{~nm}$ range. From the observed 
anisotropic angular distribution $(\beta \cong 0.97)$, the authors concluded that the orientation of the transition dipole moment reflects the $\pi^{*} \leftarrow \pi$ character of the electronic transition associated with the COO group. The significant anisotropy of the photofragments also indicates that the dissociation is faster than rotation.

Su et $a{ }^{16}{ }^{16}$ reported an infrared (IR) absorption spectrum of $\mathrm{CH}_{2} \mathrm{OO}$. By comparing their experimental results with highlevel $a b$ initio calculations, the authors concluded that the observed vibrational frequencies are more consistent with a zwitterion structure rather than a diradical structure. With IR detection, the same group ${ }^{17}$ found that the self-reaction of $\mathrm{CH}_{2} \mathrm{OO}$ is extremely fast, with a rate coefficient of $(4 \pm 2) \times$ $10^{-10} \mathrm{~cm}^{3} \mathrm{~s}^{-1}$, which reflects a unique property of the zwitterionic character.

Sheps ${ }^{7}$ used a cavity-enhanced technique to measure the UV absorption spectrum of $\mathrm{CH}_{2} \mathrm{OO}$ and observed significant vibrational structures at the long wavelength side of the absorption band. Moreover, the absorption spectrum ${ }^{7}$ differs significantly from the action spectrum reported by Beames et al. ${ }^{8}$ Sheps' argument ${ }^{7}$ is the following: "The difference between the absorption and action spectra likely arises from excitation to long-lived $\tilde{B}$ $\left({ }^{1} A^{\prime}\right)$ vibrational states that relax to lower electronic states by fluorescence or nonradiative processes, rather than by photodissociation." However, the measurement of the photoproduct anisotropy ${ }^{10}$ indicates that the photodissociation is faster than rotation which is in the picosecond time scale. Thus, the slower fluorescence process cannot compete with the fast dissociation. Furthermore, there is no theoretical evidence for the nonradiative processes. To investigate the source of this difference, we re-investigate the UV spectrum of $\mathrm{CH}_{2} \mathrm{OO}$ using two new methods.

$\mathrm{CH}_{2} \mathrm{OO}$ was prepared in a pulse-photolysis cell following the well-established method of $\mathrm{CH}_{2} \mathrm{I}_{2} / \mathrm{O}_{2}$ photolysis. ${ }^{4,16} \mathrm{CH}_{2} \mathrm{I}_{2}$ mixed with $\mathrm{O}_{2}$ and $\mathrm{N}_{2}$ was photolyzed at $248 \mathrm{~nm}$ ( $\mathrm{KrF}$ excimer laser); transient absorption spectra were recorded using a gated intensified CCD camera ( $1 \mu$ s gate width) after the probe light was dispersed using a grating monochromator ${ }^{19,20}$ (see $\mathrm{ESI}^{\dagger}$ for the experimental details). Fig. 1a shows examples of the transient absorption spectra. In Fig. 1a the most significant feature is a strong and broad absorption band peaked at $\sim 340 \mathrm{~nm}$ which showed up quickly upon photolysis and decayed with time. In addition, depletion of the $\mathrm{CH}_{2} \mathrm{I}_{2}$ precursor near $290 \mathrm{~nm}$ and formation of $\mathrm{IO}$ with distinct peaks near $430 \mathrm{~nm}$ were clearly observed, especially at long delay times.

Under our experimental conditions, $\mathrm{CH}_{2} \mathrm{OO}$ reacted quickly with itself ${ }^{17}$ and with I atoms to form $\mathrm{H}_{2} \mathrm{CO}, \mathrm{O}_{2}$, and IO. Because $\mathrm{H}_{2} \mathrm{CO}$ and $\mathrm{O}_{2}$ absorb rather weakly, the transient spectra at long delay times mainly consist of the absorption changes of $\mathrm{CH}_{2} \mathrm{I}_{2}$ (depletion) and IO (formation). Since the spectra of $\mathrm{CH}_{2} \mathrm{I}_{2}$ and IO are very different, their contributions to the transient absorption spectra can be extracted and removed (see ESI $\dagger$ for details). The remaining spectra are shown in Fig. 2a. Consistent with ref. 14, we did not observe significant difference in the $\mathrm{CH}_{2} \mathrm{OO}$ yield for different $\mathrm{O}_{2}$ mixing ratios. The identical shape of these spectra under various experimental conditions (delay times, laser fluences, and $\mathrm{O}_{2}$ pressures) strongly suggests that the spectral carrier is a

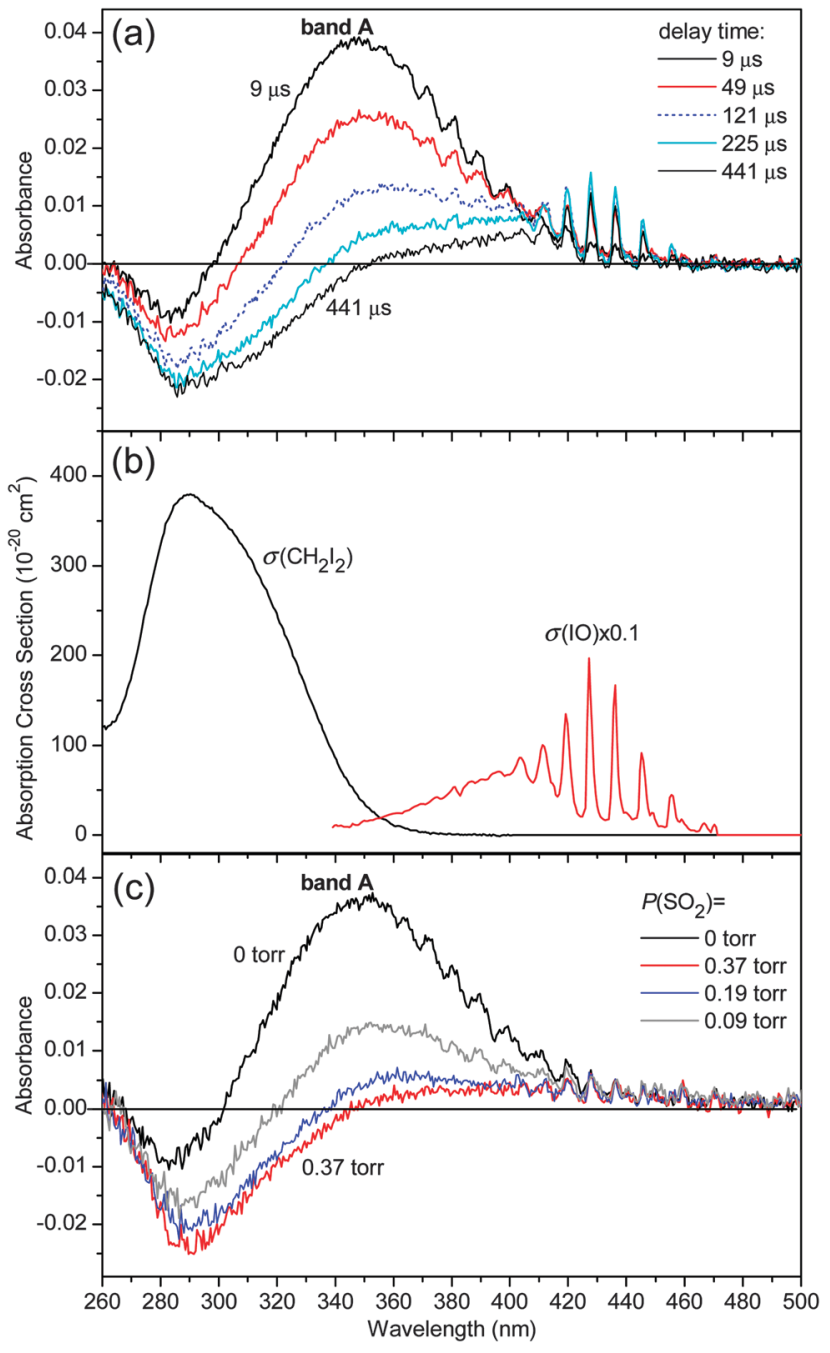

Fig. 1 (a) Examples of the transient absorption spectra. The $\left[\mathrm{CH}_{2} \mathrm{I}_{2}\right]_{0},\left[\mathrm{O}_{2}\right]_{0}$ and the total number density $n_{\text {total }}\left(\mathrm{N}_{2}\right.$ balance) are $1.6 \times 10^{15}, 3.4 \times 10^{17}$ and $2.0 \times 10^{18} \mathrm{~cm}^{-3}$, respectively. The depletion of $\mathrm{CH}_{2} \mathrm{I}_{2}(<10 \%$ of $\left.\left[\mathrm{CH}_{2} \mathrm{I}_{2}\right]_{0}\right)$ results in negative absorbance peaked at $\sim 290 \mathrm{~nm}$. The broad and strong absorption band peaked at $\sim 340 \mathrm{~nm}$ (band A) is most likely due to $\mathrm{CH}_{2} \mathrm{OO}$, which is short-lived. At longer delay times, the formation of 10 gives sharp peaks in the 410-460 nm range. (b) Published spectra of $\mathrm{CH}_{2} \mathrm{I}_{2}$ and $1 \mathrm{O}^{18}$ (c) Examples of transient absorption spectra at different $\mathrm{SO}_{2}$ concentrations. It is clear that the intensity of band $\mathrm{A}$ decreases at higher $\mathrm{SO}_{2}$ concentrations. $\left[\mathrm{CH}_{2} \mathrm{I}_{2}\right]_{0},\left[\mathrm{O}_{2}\right]_{0}$, and $n_{\text {total }}$ are $1.3 \times 10^{15}, 1.6 \times 10^{18}$, $3.3 \times 10^{18} \mathrm{~cm}^{-3}$, respectively; delay time $=10.6 \mu \mathrm{s}$.

single species. Based on the high yield of $\mathrm{CH}_{2} \mathrm{OO}$ from the $\mathrm{CH}_{2} \mathrm{I}_{2} / \mathrm{O}_{2}$ photolysis at low pressure, ${ }^{14,15}$ it is most reasonable to assign the spectral carrier to $\mathrm{CH}_{2} \mathrm{OO}$ (see below for discussion on the pressure dependence). If another absorbing species contributes significantly to these spectra, this species must exhibit kinetic behavior similar to that of $\mathrm{CH}_{2} \mathrm{OO}$.

It is known that $\mathrm{CH}_{2} \mathrm{OO}$ reacts quickly with $\mathrm{SO}_{2}\left(k_{2} \sim(3-4) \times\right.$ $\left.10^{-11} \mathrm{~cm}^{3} \mathrm{~s}^{-1}\right) \cdot{ }^{4,5}$ We utilized this kinetic signature of $\mathrm{CH}_{2} \mathrm{OO}$ to examine the spectral carrier of band A. As shown in Fig. 1c, it is clear that the intensity of band A decreases at higher $\mathrm{SO}_{2}$ concentrations. Because the absorption cross sections of $\mathrm{SO}_{2}$, $\mathrm{H}_{2} \mathrm{CO}$ and $\mathrm{SO}_{3}$ in the 316-450 nm range are much smaller 


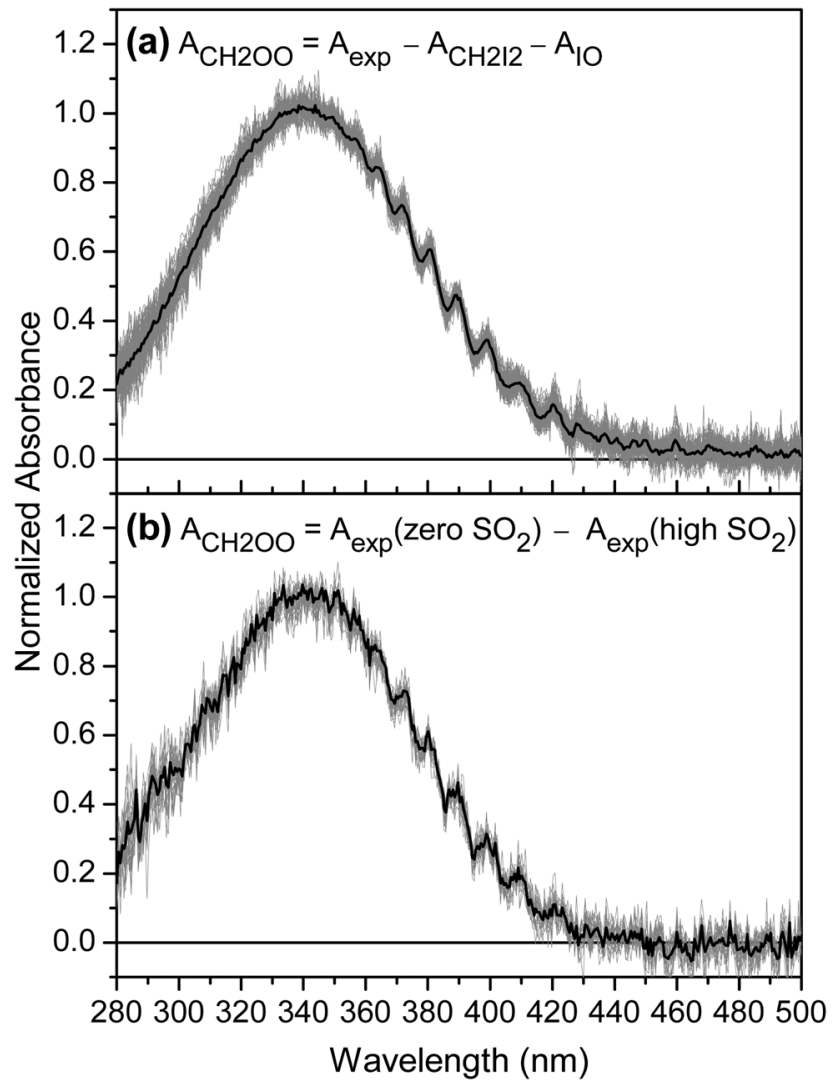

Fig. 2 (a) Background-corrected height-normalized spectra of $\mathrm{CH}_{2} \mathrm{OO}$ The variation of the experimental parameters includes combinations of delay time $(2-50 \mu \mathrm{s})$ and gas composition $\left(\mathrm{O}_{2}\right.$ percentage: $17-99 \%, \mathrm{~N}_{2}$ balance), total pressure (7.5-100 Torr), laser fluence $\left(8-16 \mathrm{~mJ} \mathrm{~cm}^{-2}\right)$, etc. A total of 99 spectra (gray lines) and their average (black line) are plotted. (b) Height-normalized spectra of $\mathrm{CH}_{2} \mathrm{OO}$ obtained by subtracting the experimental spectra at different $\mathrm{SO}_{2}$ concentrations. A total of 24 spectra (gray lines) and their average (black line) are plotted. Delay time: $6.5-50 \mu \mathrm{s}$; $\left[\mathrm{SO}_{2}\right]: 2.9 \times 10^{15}-1.2 \times 10^{16} \mathrm{~cm}^{-3}$

$\left(<1 \times 10^{-19} \mathrm{~cm}^{2}\right)$ than those of $\mathrm{CH}_{2} \mathrm{OO}$ (peak cross section $\left.>1 \times 10^{-17} \mathrm{~cm}^{2}\right),{ }^{8}$ the differences between the spectra of Fig. $1 \mathrm{c}$ should be mostly due to the absorption of $\mathrm{CH}_{2} \mathrm{OO}$. The heightnormalized curves of such difference spectra are shown in Fig. 2b. The good agreement between Fig. 2a and b confirms the above assignment.

When $\mathrm{O}_{2}$ was absent in the photolysis cell, the absorption of $\mathrm{CH}_{2} \mathrm{I}$ was present and band A could not be observed. With the published absorption cross sections of $\mathrm{CH}_{2} \mathrm{I},{ }^{21}$ the initial number density of $\mathrm{CH}_{2} \mathrm{I}$ can be estimated. Under the high $\mathrm{O}_{2}$ pressures used, $\mathrm{CH}_{2} \mathrm{I}$ reacted with $\mathrm{O}_{2}$ within a few microseconds. ${ }^{5,7,14,15}$ Therefore the number density of $\mathrm{CH}_{2} \mathrm{OO}$ can be estimated based on the published quantum yield of (R7a) $\left(\Phi_{\mathrm{CH}_{2} \mathrm{OO}}=86 \%\right.$ at 11 Torr $) .{ }^{14}$ From the estimated number density and the observed absorbance of $\mathrm{CH}_{2} \mathrm{OO}$, its absolute peak cross section can be deduced to be $(1.26 \pm 0.25) \times 10^{-17} \mathrm{~cm}^{2}$ at $340 \mathrm{~nm}$. The overall error bar is estimated to be $\pm 20 \%$ mostly due to the uncertainty in $\Phi_{\mathrm{CH}_{2} \mathrm{OO}}{ }^{14,15}$ (see $\mathrm{ESI} \dagger$ for details).

In Fig. 2a we can see that the shape of band A does not depend on the total pressure in the range of 8-100 Torr.
This observation excludes the contribution of $\mathrm{ICH}_{2} \mathrm{OO}$ because its formation is a termolecular process which has strong pressure dependence. ${ }^{14,15}$ At higher pressures (100 Torr $<P<760$ Torr), the yield of $\mathrm{CH}_{2} \mathrm{OO}$ was found to decrease with pressure (see Table S1 (ESI $\dagger$ ) for a typical example) and an additional (weaker) absorption band was observed at $\lambda<290 \mathrm{~nm}$, indicating the formation of a new species (likely $\left.\mathrm{ICH}_{2} \mathrm{OO}\right){ }^{21,22}$ The absorption of $\mathrm{ICH}_{2} \mathrm{OO}$ seems to be much weaker than that of $\mathrm{CH}_{2} \mathrm{OO}$, such that the change in spectral shape (not including the yield) with pressure is not very obvious.

The IO peaks are absent in short delay times while the absorption of $\mathrm{CH}_{2} \mathrm{OO}$ is very significant, indicating that IO is not a primary product. Based on our signal-to-noise ratio, we further constrain the primary IO yield to be less than $1 \%$, resolving some debate among published results. ${ }^{23-26}$ The formation of IO is likely due to (R8). ${ }^{5,14}$

$$
\mathrm{CH}_{2} \mathrm{OO}+\mathrm{I} \rightarrow \mathrm{H}_{2} \mathrm{CO}+\mathrm{IO}
$$

Detailed kinetic analysis is beyond the scope of this paper and will be published elsewhere.

To further quantify the absolute value of the absorption cross section of $\mathrm{CH}_{2} \mathrm{OO}$, we measured the depletion of $\mathrm{CH}_{2} \mathrm{OO}$ in a molecular beam upon laser irradiation at 308.4 and $351.8 \mathrm{~nm}$. $\mathrm{CH}_{2} \mathrm{OO}$ was detected using a quadrupole mass spectrometer equipped with an electron impact ionizer. This method ${ }^{27-29}$ has been demonstrated to be efficient in determining the photodissociation cross section of a species in a mixture without the knowledge of its concentration. Under our experimental conditions, the number of molecules $N$ after laser irradiation can be described by eqn (1).

$$
\frac{N}{N_{0}}=e^{-I \sigma \phi} \quad \frac{\Delta N}{N_{0}}=1-e^{-I \sigma \phi}
$$

Where $N_{0}$ is the number of molecules before the laser irradiation, $I$ is the laser fluence in photons per $\mathrm{cm}^{2}, \sigma$ is the absorption cross section in $\mathrm{cm}^{2}, \phi$ is the dissociation quantum yield and $\Delta N=N_{0}-N$. For $\mathrm{CH}_{2} \mathrm{I}_{2}$, the excitations at 351.8 and $308.4 \mathrm{~nm}$ correspond to repulsive (unbound) excited states which dissociate in picosecond time scales, ${ }^{30-32}$ resulting in $100 \%$ dissociation $(\phi=1)$.

Fig. 3a shows the arrival-time profiles of $\mathrm{CH}_{2} \mathrm{OO}$ at various laser fluences at $308.4 \mathrm{~nm}$. Fig. $3 \mathrm{~b}$ shows the corresponding saturation curve. A nice fit of eqn (1) to the experimental data indicates that the measurement corresponds to a single species (or multiple species having the same cross section, which is unlikely). The results at $351.8 \mathrm{~nm}$ are similar (see ESI $\dagger$ ). The complete depletion of $\mathrm{CH}_{2} \mathrm{OO}$ indicates that its dissociation yield is unity. The absolute cross section of $\mathrm{CH}_{2} \mathrm{OO}$ can be obtained by comparing its saturation curve with that of $\mathrm{CH}_{2} \mathrm{I}_{2}$, for which the cross section is known. A summary of the cross section measurement is shown in Table 1.

With the absolute cross sections of $\mathrm{CH}_{2} \mathrm{OO}$ (Table 1), we may set the spectra of Fig. 2 on the absolute scale. However, we need to consider the temperature effect of the absorption cross sections because the temperature of the molecular beam is lower than room temperature. Since the cross section of $\mathrm{CH}_{2} \mathrm{I}_{2}$ 

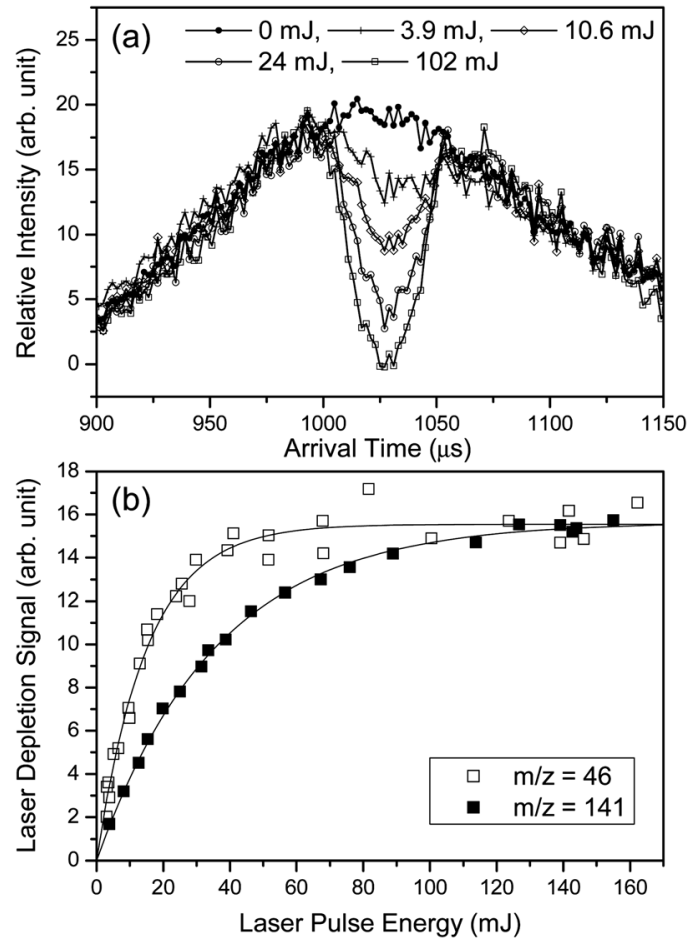

Fig. 3 (a) Arrival-time profiles of $\mathrm{CH}_{2} \mathrm{OO}$ at various laser fluences at $308.4 \mathrm{~nm}$. The parent ion of $\mathrm{CH}_{2} \mathrm{OO}$ was detected at $\mathrm{m} / \mathrm{z}=46 \mathrm{amu}$. (b) Saturation curve for the laser depletion of $\mathrm{CH}_{2} \mathrm{OO}(\mathrm{m} / \mathrm{z}=46)$ and $\mathrm{CH}_{2} \mathrm{I}_{2}$ $\left(\mathrm{m} / \mathrm{z}=141, \mathrm{CH}_{2} \mathrm{I}^{+}\right.$, a daughter ion of $\left.\mathrm{CH}_{2} \mathrm{I}_{2}\right)$ at $308.4 \mathrm{~nm}$. The $x$-axis is the laser pulse energy which is proportional to the laser fluence. The lines are the fit of eqn (1). The nice fit indicates that the laser depletion experiments are single-photon processes.

Table 1 Summary of the cross section measurements of $\mathrm{CH}_{2} \mathrm{OO}$ in a jetcooled molecular beam

\begin{tabular}{|c|c|c|}
\hline Wavelength (nm) & $\frac{\sigma \phi\left(\mathrm{CH}_{2} \mathrm{OO}\right)}{\sigma \phi\left(\mathrm{CH}_{2}\right)}$ & $\sigma\left(\mathrm{CH}_{2} \mathrm{I}_{2}\right)^{b}\left(\mathrm{~cm}^{2}\right) \sigma\left(\mathrm{CH}_{2} \mathrm{OO}\right)\left(\mathrm{cm}^{2}\right)$ \\
\hline 308.4 & $2.52+0.28^{a}$ & $(8.09+0.90) \times 10^{-18}$ \\
\hline 351.8 & $47.6 \pm 5.2$ & $\leq 2.54 \times 10^{-19} \leq(1.21 \pm 0.13) \times 10^{-17}$ \\
\hline
\end{tabular}

${ }^{a}$ The error bar is 2 standard deviation. ${ }^{b}$ Average values of ref. 33 and 34 at $T=273 \mathrm{~K}$. The temperature dependence of the UV absorption cross section of $\mathrm{CH}_{2} \mathrm{I}_{2}$ is very weak at $308.4 \mathrm{~nm}$, but moderate at $351.8 \mathrm{~nm} .{ }^{34}$ The actual cross section at $351.8 \mathrm{~nm}$ would be smaller for $\mathrm{CH}_{2} \mathrm{I}_{2}$ in a jet-cooled molecular beam.

at $308.4 \mathrm{~nm}$ does not change with temperature, ${ }^{33,34}$ we can use the near-room-temperature value for the cross section of $\mathrm{CH}_{2} \mathrm{I}_{2}$ in a molecular beam. The UV absorption band of $\mathrm{CH}_{2} \mathrm{OO}$ can be assigned to the intense $\tilde{\mathrm{B}} \leftarrow \tilde{\mathrm{X}}$ transition $^{8,22}$ which is analogous to the Hartley band of $\mathrm{O}_{3}$. The cross section of the $\mathrm{O}_{3}$ Hartley band has a quite weak temperature dependence. ${ }^{18,35}$ The peak cross section (at $254 \mathrm{~nm}$ ) of $\mathrm{O}_{3}$ increases by $\sim 1.5 \%$ when the temperature decreases from $293 \mathrm{~K}$ to $203 \mathrm{~K}$. For the main region of the Hartley band (215-288 nm, $1 \times 10^{-18} \mathrm{~cm}^{2}<\sigma<1.1 \times$ $10^{-17} \mathrm{~cm}^{2}$ ), the temperature effect is within $5 \%(203-293 \mathrm{~K}) .{ }^{18,35}$ Similarly, it is expected that the temperature dependence of the $\mathrm{CH}_{2} \mathrm{OO}$ cross sections is weak near the peak. Therefore, we choose the cross section at $308.4 \mathrm{~nm}$ to scale the average spectra of Fig. 2 and to plot the scaled spectra in Fig. 4 . We believe that the $\mathrm{SO}_{2}$ scavenging method would give a more reliable spectrum of $\mathrm{CH}_{2} \mathrm{OO}$ (see Table S3 (ESI $\dagger$ ) for numerical values) while the result of the self-reaction method is very similar. The peak value of the scaled spectrum is $(1.23 \pm 0.18) \times 10^{-17} \mathrm{~cm}^{2}$ at $340 \mathrm{~nm}$. We assume an error bar of $\pm 15 \%$ to include possible variations due to the temperature effect. This value is consistent with the peak cross section of $(1.26 \pm 0.25) \times 10^{-17} \mathrm{~cm}^{2}$ obtained in the transient absorption experiment of this work based on the estimated $\mathrm{CH}_{2} \mathrm{OO}$ number density.

Previous UV absorption ${ }^{7}$ and action spectra ${ }^{8}$ of $\mathrm{CH}_{2} \mathrm{OO}$ exhibit significant differences. Beames et al. ${ }^{8}$ measured the laser depletion of $\mathrm{CH}_{2} \mathrm{OO}$ in a similar molecular beam and obtained an action spectrum of $\mathrm{CH}_{2} \mathrm{OO}$. However Beames et al. ${ }^{8}$ only estimated the laser fluence from their laser (a dye laser) pulse energy and spot size. The beam spot of a dye laser is usually highly non-uniform. Without using a laser beam profiler, it is difficult to quantify the actual laser fluence. Beames et $a .^{8}$ might underestimate their laser fluence and thus overestimate the $\mathrm{CH}_{2} \mathrm{OO}$ cross section. In this work, we utilized a reference molecule to effectively calibrate the laser fluence and to cancel the effect of non-uniform laser spot. ${ }^{36}$ Therefore, our results should be more accurate.

Fig. 4 compares our results with those of Sheps ${ }^{7}$ and Beames et $a l .{ }^{8}$ The scaled spectrum of Beames et $a l^{8}$ is weaker at $\lambda \geq$ $360 \mathrm{~nm}$. The temperature effect may be one possible reason for this difference. While the intense Hartley band of $\mathrm{O}_{3}$ has a rather weak temperature dependence, the weak Huggins band or the long-wavelength tail of the Hartley band (310-380 $\mathrm{nm}$ ) has very strong temperature dependence (smaller cross sections at lower temperatures). ${ }^{18,35}$ If the temperature dependence of the $\mathrm{CH}_{2} \mathrm{OO}$ cross sections at $\lambda \geq 360 \mathrm{~nm}$ is as strong as that of the Huggins band of $\mathrm{O}_{3}$, this may explain why the spectrum of Beames et $a .^{8}$ is weaker in this wavelength range. Another possibility mentioned by Sheps ${ }^{7}$ is a decrease in the dissociation yield at long wavelengths. Although this might explain the discrepancy between the absorption and action spectra, it is inconsistent with the product anisotropy measurement by Lehman et al. ${ }^{10}$ which shows that the UV photodissociation of $\mathrm{CH}_{2} \mathrm{OO}$ is faster than its rotation ( $\sim$ picosecond). Thus, a nonunity dissociation yield would require a fast process that can compete with photodissociation. Fluorescence is too slow to fulfill this condition. Other fast non-radiative processes are unlikely but cannot be fully ruled out at this moment. More evidence and investigations are needed.

Sheps $^{7}$ used a newly-built cavity-enhanced absorption spectrometer to measure the transient absorption spectra of the $\mathrm{CH}_{2} \mathrm{I}_{2}$ / $\mathrm{O}_{2}$ photolysis system. Sheps ${ }^{7}$ determined the absolute $\mathrm{CH}_{2} \mathrm{OO}$ spectrum based on the measured $\mathrm{CH}_{2}$ I spectrum (when $\mathrm{O}_{2}$ was absent) and an estimated (90 \pm 10$) \%$ yield of transforming $\mathrm{CH}_{2} \mathrm{I}$ to $\mathrm{CH}_{2} \mathrm{OO}$ at 5 Torr. Qualitatively, the shape of Sheps' spectrum $^{7}$ is similar to ours, particularly the structures at the long-wavelength side (the peak positions are matched). However, the short-wavelength side of Sheps' spectrum ${ }^{7}$ decays much faster than that in this work. Furthermore, the reported peak cross section and position of the $\mathrm{CH}_{2} \mathrm{OO}$ spectrum by 


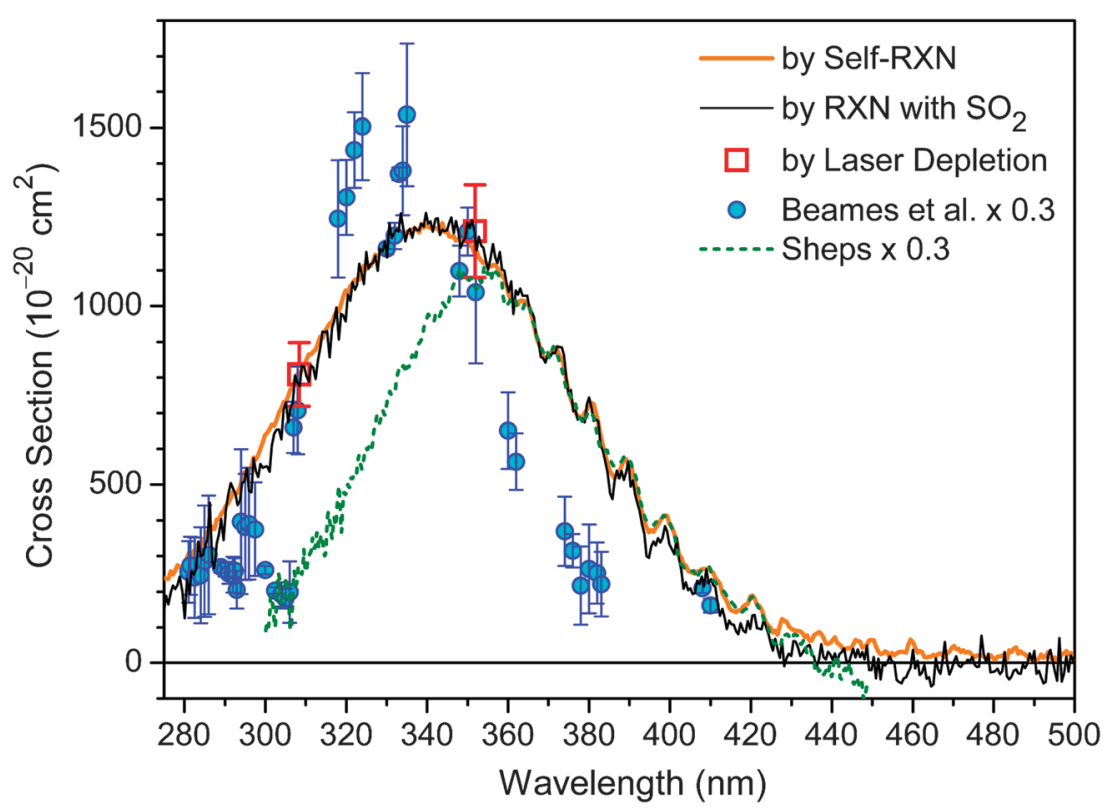

Fig. 4 Absorption spectrum of $\mathrm{CH}_{2} \mathrm{OO}$. The thick orange and thin black lines are the average curves of Fig. $2 a$ and b, respectively. For the thin black line (numerical values can be found in $\mathrm{ESI} \dagger$ ), the absorbance due to the reacted $\mathrm{SO}_{2}$ has been removed, based on the mass balance of (R2) (see ESI $\dagger$ ). Square symbols are the absolute cross sections from the molecular beam-laser depletion measurements (Table 1). The black and orange lines are scaled to match the absolute cross section at $308.4 \mathrm{~nm}$. The results of Sheps ${ }^{7}$ and Beames et al. ${ }^{8}$ are scaled by a factor of 0.3 for easier comparison. The temperature of the photolysis cell was $295 \mathrm{~K}$. The molecular beams of this work and Beames et al. ${ }^{8}$ were jet-cooled (estimated rotational temperature $\sim 10 \mathrm{~K}$ ).

Sheps $^{7}\left[(3.6 \pm 0.9) \times 10^{-17} \mathrm{~cm}^{2}\right.$ at $\left.355 \mathrm{~nm}\right]$ are different from our values. The source of the discrepancies is not clear. It might arise from the complexity of the cavity-enhanced measurement.

There are at least 7 vibrational peaks observable on the longwavelength side of the UV absorption band of $\mathrm{CH}_{2} \mathrm{OO}$ (Fig. 2 and 4 ). The widths of these vibrational peaks are significantly wider than the instrument resolution of $\sim 2 \mathrm{~nm}$. Similar structures have been reported by $\operatorname{Sheps}^{7}$ at a slightly lower resolution and signal-to-noise ratio. The positions of the most well-defined peaks are 363.7, 372.0, 380.7, 389.2, 399.0, 409.3, $420.5 \mathrm{~nm}\left(27495,26882,26267,25694,25063,24432,23781 \mathrm{~cm}^{-1}\right)$. The average peak separation is about $620 \mathrm{~cm}^{-1}$. Analogous to the Huggins band of $\mathrm{O}_{3}$, these vibrational structures may arise from some periodic motions on the excited potential energy surface, most likely the $\tilde{\mathrm{B}}\left({ }^{1} \mathrm{~A}^{\prime}\right)$ surface. The widths of the vibrational peaks may originate from congested vibrational structures (vibrational modes involving $\mathrm{O}-\mathrm{O}$ stretching and $\mathrm{C}-\mathrm{O}-\mathrm{O}$ bending) ${ }^{22}$ or rotational contours at room temperature. For the $\mathrm{O}_{3}$ Huggins band, the widths of the vibrational peaks become narrower at low temperatures. ${ }^{18,35}$ It will be interesting to see how the peak structures change at lower temperatures for $\mathrm{CH}_{2} \mathrm{OO}$.

In summary, more accurate UV absorption cross sections of the simplest Criegee intermediate $\mathrm{CH}_{2} \mathrm{OO}$ are reported. The peak cross section is determined to be $(1.23 \pm 0.18) \times 10^{-17} \mathrm{~cm}^{2}$ at $340 \mathrm{~nm}$. This value is significantly smaller than previous reports, ${ }^{7,8}$ implying slower photolysis rates in the atmosphere than previously expected. Nonetheless, this intense absorption band of $\mathrm{CH}_{2} \mathrm{OO}$ overlaps well with the incoming solar spectrum, resulting in efficient photolysis of this Criegee intermediate. The clear vibrational structures on the long-wavelength side of the $\mathrm{CH}_{2} \mathrm{OO}$ spectrum provide a fingerprint feature for spectroscopic identification of this elusive intermediate.

\section{Acknowledgements}

This work was supported by Academia Sinica and Ministry of Science and Technology, Taiwan (NSC100-2113-M-001-008-MY3). The authors thank Miss Shu-Yi Meng for assistance in data acquisition and Profs Yuan T. Lee and Yuan-Pern Lee for discussions.

\section{References}

1 R. Criegee, Angew. Chem., Int. Ed. Engl., 1975, 14, 745-752.

2 R. Criegee and G. Wenner, Liebigs Ann. Chem., 1949, 564, 9-15.

3 C. A. Taatjes, D. E. Shallcross and C. Percival, Phys. Chem. Chem. Phys., 2014, 16, 1704-1718, DOI: 10.1039/C3CP52842A.

4 O. Welz, J. D. Savee, D. L. Osborn, S. S. Vasu, C. J. Percival, D. E. Shallcross and C. A. Taatjes, Science, 2012, 335, 204-207.

5 D. Stone, M. Blitz, L. Daubney, N. U. M. Howesa and P. Seakins, Phys. Chem. Chem. Phys., 2014, 16, 1139-1149, DOI: 10.1039/c3cp54391a.

6 B. Ouyang, M. W. McLeod, R. L. Jones and W. J. Bloss, Phys. Chem. Chem. Phys., 2013, 15, 17070-17075.

7 L. Sheps, J. Phys. Chem. Lett., 2013, 4, 4201-4205.

8 J. M. Beames, F. Liu, L. Lu and M. I. Lester, J. Am. Chem. Soc., 2012, 134, 20045-20048.

9 J. M. Beames, F. Liu, L. Lu and M. I. Lester, J. Chem. Phys., 2013, 138, 244307. 
10 J. H. Lehman, H. Li, J. M. Beames and M. I. Lester, J. Chem. Phys., 2013, 139, 141103.

11 C. J. Percival, et al., Faraday Discuss., 2013, 165, 45-73.

12 M. Boy, D. Mogensen, S. Smolander, L. Zhou, T. Nieminen, P. Paasonen, C. Plass-Dülmer, M. Sipilä, T. Petäjä, L. Mauldin, H. Berresheim and M. Kulmala, Atmos. Chem. Phys., 2013, 13, 3865-3879.

13 C. A. Taatjes, G. Meloni, T. M. Selby, A. J. Trevitt, D. L. Osborn, C. J. Percival and D. E. Shallcross, J. Am. Chem. Soc., 2008, 130, 11883-11885.

14 D. Stone, M. Blitz, L. Daubney, T. Ingham and P. Seakins, Phys. Chem. Chem. Phys., 2013, 15, 19119-19124.

15 H. Huang, A. J. Eskola and C. A. Taatjes, J. Phys. Chem. Lett., 2012, 3, 3399-3403; H. Huang, B. Rotavera, A. J. Eskola and C. A. Taatjes, J. Phys. Chem. Lett., 2013, 4, 3824.

16 Y.-T. Su, Y.-H. Huang, H. A. Witek and Y.-P. Lee, Science, 2013, 340, 174-176.

17 Y.-T. Su, H.-Y. Lin, R. Putikam, H. Matsui, M. C. Lin and Y.-P. Lee, Nat. Chem., 2014, DOI: 10.1038/nchem.1890.

18 S. P. Sander, J. Abbatt, J. R. Barker, J. B. Burkholder, R. R. Friedl, D. M. Golden, R. E. Huie, C. E. Kolb, M. J. Kurylo, G. K. Moortgat, V. L. Orkin and P. H. Wine, Chemical Kinetics and Photochemical Data for Use in Atmospheric Studies, Evaluation Number 17, JPL Publication 10-6, Jet Propulsion Laboratory, Pasadena, 2011, http://jpldataeval. jpl.nasa.gov.

19 M.-N. Su and J. J. Lin, Rev. Sci. Instrum., 2013, 84, 086106.

20 M.-N. Su and J. J. Lin, GSTF Journal of Chemical Sciences (JChem), 2013, 1, 52-57, DOI: 10.5176/2339-5060_1.1.6, ISSN: 2339-5060.

21 J. Sehested, T. Ellermann and O. J. Nielsen, Int. J. Chem. Kinet., 1994, 26, 259-272.
22 E. P. F. Lee, D. K. W. Mok, D. E. Shallcross, C. J. Percival, D. L. Osborn, C. A. Taatjes and J. M. Dyke, Chem. - Eur. J., 2012, 18, 12411-12423.

23 T. J. Gravestock, M. A. Blitz, W. J. Bloss and D. E. Heard, ChemPhysChem, 2010, 11, 3928.

24 T. J. Dillon, M. E. Tucceri, R. Sander and J. N. Crowley, Phys. Chem. Chem. Phys., 2008, 10, 1540.

25 A. J. Eskola, D. Wojcik-Pastuszka, E. Ratajczak and R. S. Timonen, Phys. Chem. Chem. Phys., 2006, 8, 1416-1424.

26 S. Enami, T. Yamanaka, S. Hashimoto, M. Kawasaki, K. Tonokura and H. Tachikawa, Chem. Phys. Lett., 2007, 445, 152-156.

27 H.-Y. Chen, C.-Y. Lien, W.-Y. Lin, Y. T. Lee and J. J. Lin, Science, 2009, 324, 781.

28 J. J. Lin, A. F. Chen and Y. T. Lee, Chem. -Asian J., 2011, 6, 1664.

29 B. Jin, M.-N. Su and J. J. Lin, J. Phys. Chem. A, 2012, 116, 12082-12088.

30 J. Zhang, E. J. Heller, D. Huber, D. G. Imre and D. Tannor, J. Chem. Phys., 1988, 89, 3602.

31 H. F. Xu, Y. Guo, S. L. Liu, X. X. Ma, D. X. Dai and G. H. Sha, J. Chem. Phys., 2002, 117, 5722.

32 J. H. Lehman, H. Li and M. I. Lester, Chem. Phys. Lett., 2013, 590, 16-21.

33 J. C. Mössinger, D. E. Shallcross and R. A. Cox, J. Chem. Soc., Faraday Trans., 1998, 94, 1391-1396.

34 C. M. Roehl, J. B. Burkholder, G. K. Moortgat, A. R. Ravishankara and P. J. Crutzen, J. Geophys. Res., 1997, 102, 12819-12829.

35 W. Chehade, B. Gür, P. Spietz, V. Gorshelev, A. Serdyuchenko, J. P. Burrows and M. Weber, Atmos. Meas. Tech., 2013, 6, 1623-1632.

36 B. Jin, I.-C. Chen, W.-T. Huang, C.-Y. Lien, N. Guchhait and J. J. Lin, J. Phys. Chem. A, 2010, 114, 4791. 